\title{
Managing an Older Adult with Cancer: Considerations for Radiation Oncologists
}

\author{
Sanders Chang, ${ }^{1}$ Nathan E. Goldstein, ${ }^{1,2}$ and Kavita V. Dharmarajan ${ }^{1,2,3}$ \\ ${ }^{1}$ Icahn School of Medicine at Mount Sinai, New York, NY, USA \\ ${ }^{2}$ Brookdale Department of Geriatrics and Palliative Medicine, Mount Sinai Hospital, New York, NY, USA \\ ${ }^{3}$ Department of Radiation Oncology, Mount Sinai Hospital, New York, NY, USA
}

Correspondence should be addressed to Kavita V. Dharmarajan; kavita.dharmarajan@mountsinai.org

Received 11 July 2017; Revised 3 October 2017; Accepted 16 November 2017; Published 13 December 2017

Academic Editor: Angeles Rovirosa

Copyright (C) 2017 Sanders Chang et al. This is an open access article distributed under the Creative Commons Attribution License, which permits unrestricted use, distribution, and reproduction in any medium, provided the original work is properly cited.

\begin{abstract}
Older adults with cancer present a unique set of management complexities for oncologists and radiation oncologists. Prognosis and resilience to cancer treatments are notably dependent on the presence or risk of "geriatric syndromes," in addition to cancer stage and histology. Recognition, proper evaluation, and management of these conditions in conjunction with management of the cancer itself are critical and can be accomplished by utilization of various geriatric assessment tools. Here we review principles of the geriatric assessment, common geriatric syndromes, and application of these concepts to multidisciplinary oncologic treatment. Older patients may experience toxicities related to treatments that impact treatment effectiveness, quality of life, treatment-related mortality, and treatment compliance. Treatment-related burdens from radiotherapy are increasingly important considerations and include procedural demands, travel, costs, and temporary or permanent loss of functional independence. An overall approach to delivering radiotherapy to an older cancer patient requires a comprehensive assessment of both physical and nonphysical factors that may impact treatment outcome. Patient and family-centered communication is also an important part of developing a shared understanding of illness and reasonable expectations of treatment.
\end{abstract}

\section{Introduction}

Vignette. Robert Smith is a 75-year-old functionally independent gentleman with recently diagnosed Stage II laryngeal carcinoma. His radiation oncologist prescribed him a schedule of $70 \mathrm{~Gy}$ in $2 \mathrm{~Gy}$ fractions [1]. Mr. Smith tolerated the initial weeks of radiation therapy well; however, by week 4, he developed moderate mucositis and his oral intake significantly decreased. This led to subsequent dehydration, resulting in an episode of syncope that caused him to fall down a flight of stairs. Mr. Smith was hospitalized with a fractured hip and underwent surgery to stabilize the fractured bone. He required a 2-month stay in a nursing facility due to loss of his functional independence.

This above vignette is an unfortunately common scenario that could complicate the cancer treatment process for an older patient. An event such as Mr. Smith's fall may at first seem to be an ill-timed coincidence unrelated to cancer treatment. In reality, it is a consequence of his complex multifaceted health and functional status. Many older adults risk a predicament similar to Mr. Smith's in the face of cancer treatment. As radiation oncologists, how can we better conceptualize assessment and management for patients like $\mathrm{Mr}$. Smith and reduce the risk of events leading to a loss of functional independence?

Acknowledgment of older adults with cancer as a distinct patient population requiring knowledge of specialized principles in cancer management is increasingly important given that the population of the United States is aging at an increasing rate. A projected 74.1 million $(20.6 \%)$ of Americans will be 65 or older in 2030, an increase from 46.2 million (14.5\%) in 2014; 9.1 million (2.5\%) of Americans will be 85 or older in 2030, an increase from 6.2 million (1.9\%) in 2014 [2]. Given the linear relationship between increasing age and cancer risk, the number of older adults with cancer will increase dramatically over the next decade. Between 2010 
and 2030, an anticipated increase of $67 \%$ will be expected in the cancer incidence for patients 65 years or older (1.0 million to 1.6 million instances) [3]. A significant proportion of these patients will receive radiation therapy as part of their treatment. It has been projected that from 2010 to 2020, there will be a $38 \%$ rise in the number of adults 65 or older who will be treated with radiation therapy as an initial treatment course (282,000 to 388,000 instances) [4].

The key to approaching management of older patients with cancer is to understand the unique differences that these patients have compared to their younger counterparts, both with respect to their tumor biology and overall health and functional status. Older patients have distinct physical, psychosocial, and economic needs that play an important part in their well-being. In order to comprehensively address their care, radiation oncologists may find it helpful to have a working understanding of the available tools for performing a geriatric assessment and the common geriatric syndromes such as falls, frailty, and polypharmacy that might affect treatment outcomes of older adults. A common pitfall that arises in oncologic management of older adults is making decisions about medical management based primarily on the type and stage of cancer and chronological age. However, decision-making in this special population is significantly more nuanced. Assessment of functional age [5], which is distinct from chronological age and is determined by a combination of factors including performance status, comorbidities, and presence of geriatric syndromes, is of paramount importance. This article will review the utility of geriatric assessment tools that may help predict a patient's ability to tolerate cancer treatments and side effects, the geriatric syndromes that can come into play during cancer treatment, and the specific considerations regarding the delivery of radiation therapy and chemotherapy to older adults.

\section{Phenotype of the Older Adult}

Aging is a coordinated process associated with many physiological and biologic changes in the human body. Over time, organs gradually lose their maximal function and respond less resiliently to external stresses [6]. At the cellular level, senescence may lead to reduced replication efficiency and recovery of tissues. At the molecular level, a lifetime of DNA replication, damage, and repair can pave the way to deleterious mutations that can ultimately lead to cancer. These changes play a part in the pathological development of morbidity and mortality in the older patient as well as overall resiliency and recovery.

2.1. Morbidity in the Older Adult. With a growing population of older adults, morbidity is becoming an increasing concern in the geriatric population. Compared to their younger counterparts, older adults harbor a greater number of chronic conditions. Many suffer from syndromes unique to the geriatric population such as frailty, dementia, and falls and can rely increasingly upon caregiving. From a 2014 report on people aged 65 years or older residing in the United States, $55.9 \%$ were living with hypertension, $49.0 \%$ with arthritis, $29.4 \%$ with heart disease, $23.4 \%$ with cancer, and $20.8 \%$ with diabetes [2]. More than $50 \%$ of Medicare beneficiaries have more than one chronic condition [7]. Increasing level of multimorbidity is positively correlated with increasing number of inpatient admissions, postacute care services, home health visits, emergency room visits, and readmissions to the hospital within 30 days of discharge [7]. This overall decrease in health status of older adults results in a higher utilization of health care services. On average, older patients incur more annual health care costs, which consist of hospital stays, doctors' visits, nursing home or visiting nurse services, and prescription drugs [2]; yet at the same time, they may not have steady financial resources to pay for these increasing costs, some of which may be out-of-pocket expenses.

\section{Geriatric Assessment}

3.1. Principles of the Geriatric Assessment. An older person's ability to perform activities of daily living may impact the tolerability of cancer treatments. An awareness of the multidimensional contributors to the overall health status of an older adult (separate from the cancer stage, Karnofsky Performance Status at the time of visit, and an individual's chronological age) may allow for conceptualization of more optimally tailored treatment recommendations for an individual patient and also may better prepare the patient and caregivers for what to expect during treatment and afterwards. A full assessment of the geriatric patient covers each of the following domains: physical condition, cognitive function, functional status, nutritional status, psychosocial health, economic status, physical environment, caregiver support, and spirituality [6]. Specific issues that might have important implications during a patient's treatment and thus need to be considered during an oncologic geriatric assessment include but are not limited to impairments of vision and hearing, urinary incontinence, constipation, changes in gait, history of falls, tremor, neurocognitive deficits, and changes in weight.

3.2. Tools for the Geriatric Assessment. The "gold standard" for evaluating older adults is the comprehensive geriatric assessment (CGA). The origin of the CGA dates back to the 1940 s by Dr. Marjory Warren in the United Kingdom, who noticed a need to better manage older patients in the hospital who were bedridden and chronically ill [49]. She developed one of the first geriatric units to help mobilize these patients to undergo proper medical and rehabilitative care, thereby paving the way for a more systemic means of evaluating geriatric patients. A CGA involves a methodical approach of in-depth evaluation that includes an assessment of four health domains: physical health, functional status, psychological well-being, and socioeconomic factors [6]. Many screening tools and questionnaires can be used to assess these different health domains (summarized in Table 1), although not all of them are necessarily required to perform a thorough CGA.

The use of such a systematic way to conduct a full geriatric assessment has utility in predicting survival outcomes among older patients undergoing cancer treatment [50]. For instance, better-performing older adults had improved survival following surgery for breast or colorectal cancers, 
TABLE 1: Examples of available screening tools currently used to conduct a geriatric assessment (CGA), adapted from [8,9].

\begin{tabular}{|c|c|c|}
\hline $\begin{array}{l}\text { General health } \\
\text { status domain }\end{array}$ & $\begin{array}{l}\text { Specific domain } \\
\text { components }\end{array}$ & Screening tools available for assessment of the specific domain components \\
\hline \multirow{3}{*}{$\begin{array}{l}\text { Physical health } \\
\text { status }\end{array}$} & Comorbidities & $\begin{array}{l}\text { Charlson Comorbidity Index (CCI) [10], Cumulative Illness Rating Scale for } \\
\text { Geriatrics (CIRS-G) [11] }\end{array}$ \\
\hline & Nutrition & $\begin{array}{l}\text { Subjective Global Assessment (SGA) [12], Mininutritional Assessment (MNA) [13], } \\
\text { Geriatric Nutritional Risk Index (GNRI) [14] }\end{array}$ \\
\hline & Medications & Review history of medications, Beers criteria [15] \\
\hline \multirow{6}{*}{$\begin{array}{l}\text { Functional } \\
\text { status }\end{array}$} & Frailty & $\begin{array}{l}\text { Frailty Index (FI) by deficit accumulation [16, 17], Fried Frailty Index [18], } \\
\text { Vulnerable Elders Scale-13 (VES-13) [19] }\end{array}$ \\
\hline & $\begin{array}{l}\text { Activities of daily living } \\
\text { (ADLs) }\end{array}$ & Barthel's Index Rating Scale [20], Katz Index of Independence in ADLs [21] \\
\hline & $\begin{array}{l}\text { Instrumental activities of } \\
\text { daily living (IADLs) }\end{array}$ & Functional Activity Questionnaire [22], Rapid Disability Rating Scales [23] \\
\hline & Falls and balance test & $\begin{array}{l}\text { History of falls, Berg Balance Scale [24], Timed Up and Go Test [25], Tinetti Gait } \\
\text { and Balance Test [26], Fall Risk Assessment Scale for the Elderly (FRASE) [27], Fall } \\
\text { Risk Index [28] }\end{array}$ \\
\hline & Gait speed & Average In-home Gait Speed (AIGS) [29] \\
\hline & Strength & Handgrip Test [30] \\
\hline \multirow{2}{*}{$\begin{array}{l}\text { Psychological } \\
\text { well-being }\end{array}$} & Cognitive function & $\begin{array}{l}\text { Minimental Status Examination (MMSE) [31], Montreal Cognitive Assessment } \\
\text { (MoCA) [32], Informant Questionnaire on Cognitive Decline in the Elderly } \\
\text { (IQCODE) [33], Simple Clock Drawing Test }\end{array}$ \\
\hline & Depression and anxiety & $\begin{array}{l}\text { Geriatric Depression Scale (GDS) [34, 35], Hamilton Rating Scale for Depression } \\
\text { (HRSD) [36], Geriatric Anxiety Inventory (GAI) [37], Geriatric Anxiety Scale [38], } \\
\text { Hospital Anxiety and Depression Scale [39] }\end{array}$ \\
\hline \multirow{2}{*}{$\begin{array}{l}\text { Socioeconomic } \\
\text { status }\end{array}$} & Social support & General questionnaire, Medical Outcomes Survey Social Support [40] \\
\hline & Environment & $\begin{array}{l}\text { Financial capabilities, transport facilities, technology use, home safety } \\
\text { questionnaires }\end{array}$ \\
\hline
\end{tabular}

whereas poorer-performing older adults had a higher postoperative mortality risk [50, 51]. Risk-stratifying patients based on a CGA may uncover certain parameters (e.g., low vitamin D levels) that could be intervened upon and thereby minimize treatment-related toxicities $[52,53]$. Evidence has shown that performing a CGA can alter up to $49 \%$ of patients' initial treatment plans [54]. In radiation therapy, conducting a CGA has the potential to predict side effects and tolerability to radiation. A recent Turkish study found that certain parameters measured in the CGA, such as low vitamin D levels and slower 6-meter length gait speeds, are associated with postradiation esophagitis and emesis, respectively [53].

Performing a CGA can be time consuming and resource intensive, and the use of these tools may require additional training. Several abbreviated screening tools have been proposed which identify patients who would likely benefit from a full CGA (Table 2). Each of the tools has undergone assessment of its sensitivity and specificity [41]. For example, the G8 had a sensitivity ranging from $65 \%$ to $92 \%$ and specificity ranging from $3 \%$ to $75 \%$. VES-13 had a sensitivity ranging from $39 \%$ to $88 \%$ and specificity ranging from $62 \%$ to $100 \%$. Because of their varying rates of sensitivity and specificity, there is ongoing debate on whether these screening tools can be used alone or in conjunction with a full geriatric assessment $[41,55]$. Despite its wide variation in sensitivity range, direct comparisons between G8 and other screening tools show that G8 performs at a significantly greater or equal sensitivity [41, 43]. G8 may be the preferred screening tool in a radiation oncology setting, given its performance and efficiency.

The European Organisation for Research and Treatment of Cancer QLQ-C30 (EORTC QLQ-C30) is another widely used tool that can assess the quality of life for cancer patients undergoing treatment but is nonspecific for older adults [56]. An updated version of this tool (EORTC QLQ-ELD14) validated for older patients has been in use since 2013 but is not specifically designed to assess for geriatric syndromes [57].

\section{Geriatric Syndromes}

An explanation for the increased morbidity and mortality of older patients lies in their susceptibility to a set of conditions known as "geriatric syndromes." These ailments are a central concern in geriatric care and include frailty, dementia, syncope, delirium, falls, dizziness, sleep disorders, and pressure ulcers [6]. Frailty is a well-studied geriatric syndrome considered highly relevant in cancer treatment and specifically in radiation therapy.

4.1. Frailty. As patients age, changes in physical health and functional abilities become increasingly complex and thereby cannot be easily attributed to a single underlying clinical condition (such as cancer). A unifying factor that can explain 
TABLE 2: Selected screening tools currently available to perform an abbreviated geriatric assessment, adapted from [41].

\begin{tabular}{|c|c|c|c|}
\hline Screening tools & Purpose & Method of assessment & References \\
\hline $\begin{array}{l}\text { G8 screening } \\
\text { questionnaire }\end{array}$ & $\begin{array}{c}\text { Identify geriatric impairments in } \\
\text { elderly patients across all CGA } \\
\text { domains }\end{array}$ & $\begin{array}{l}\text { 8-item clinical assessment conducted by health care } \\
\text { provider: food intake, weight loss, mobility, } \\
\text { neuropsychological problems, body mass index, } \\
\text { medication usage, self-perception of health, and age }\end{array}$ & {$[42]$} \\
\hline $\begin{array}{l}\text { Vulnerable elders } \\
\text { survey-13 }\end{array}$ & $\begin{array}{l}\text { Identify elderly patients who are } \\
\text { "vulnerable," that is, at risk of } \\
\text { functional worsening or death } \\
\text { over } 2 \text { years }\end{array}$ & $\begin{array}{l}\text { 12-item clinical assessment conducted by health care } \\
\text { provider: physical activities, ADL/IADLS, age, } \\
\text { self-rated health, and comorbidities }\end{array}$ & {$[19]$} \\
\hline $\begin{array}{l}\text { Flemish version of the } \\
\text { triage risk screening } \\
\text { tool }\end{array}$ & $\begin{array}{l}\text { Identify elderly patients who are } \\
\text { at risk for readmission following } \\
\text { discharge }\end{array}$ & $\begin{array}{l}\text { 5-item clinical assessment conducted by health care } \\
\text { provider: presence of cognitive impairment, living } \\
\text { alone or no caregiver available, walking difficulty and } \\
\text { history of falls, recent hospitalization, and } \\
\text { polypharmacy ( } \geq 5 \text { medications) }\end{array}$ & {$[43,44]$} \\
\hline $\begin{array}{l}\text { Study of osteoporotic } \\
\text { fractures index }\end{array}$ & Measure "prefrailty" and "frailty" & $\begin{array}{l}\text { 3-item clinical assessment conducted by health care } \\
\text { provider: weight loss, inability to rise from chair, and } \\
\text { poor energy }\end{array}$ & {$[45,46]$} \\
\hline $\begin{array}{l}\text { Groningen frailty } \\
\text { indicator }\end{array}$ & $\begin{array}{l}\text { Measure physical, social, and/or } \\
\text { psychological impairment }\end{array}$ & $\begin{array}{l}\text { 15-item clinical assessment conducted by health care } \\
\text { provider: mobility, vision, hearing, nutrition, } \\
\text { comorbidities, cognition, psychosocial, and physical } \\
\text { fitness }\end{array}$ & {$[47]$} \\
\hline Fried frailty criteria & Measure "frailty" & $\begin{array}{l}\text { 5-item clinical assessment conducted by health care } \\
\text { provider: weight loss, handgrip, gait speed, exhaustion, } \\
\text { and physical performance }\end{array}$ & {$[18]$} \\
\hline $\begin{array}{l}\text { Abbreviated } \\
\text { comprehensive } \\
\text { geriatric assessment } \\
\text { (aCGA) }\end{array}$ & $\begin{array}{l}\text { Select items from the CGA to } \\
\text { expedite assessment }\end{array}$ & $\begin{array}{l}\text { 15-item clinical assessment conducted by health care } \\
\text { provider: from Geriatric Depression Scale [34], MMSE } \\
\text { [31], ADLs, and IADLs }\end{array}$ & {$[48]$} \\
\hline
\end{tabular}

these multifaceted changes is the concept of frailty, which is defined by geriatricians as a vulnerable, age-related state in which one is less able to maintain homeostatic equilibrium, resulting in unfavorable outcomes such as falls and disability $[6,18,58,59]$. Phenotypically, the frail patient will exhibit a range of manifestations, such as loss in energy, physical strength, and weight, and inability to perform common functional tasks. In recent years, frailty is appreciated more broadly as a multidimensional concept of illness spanning biological, physiological, psychological, and social domains of the older adult [60-62].

The prevalence of frailty in the geriatric population is unclear. A systematic review by Collard et al. of populations in various countries (e.g., United States, Canada, and United Kingdom) found the prevalence of frailty to be $4.0 \%$ to $59.1 \%$ among community-dwelling adults 65 or older [63]. This wide range is attributed to the observation that a proportion of the studies defined frailty solely as a physical phenotype, which had a weighted prevalence of $9.9 \%$, whereas another proportion defined it as both a physical and psychological phenomenon, which resulted in a weighted prevalence of $13.6 \%$.

Several metrics have been proposed to quantify the degree of frailty in a patient [64]. The two most prominent scales are the CGA-based Frailty Index (FI), which assesses the accumulation of deficits in various areas spanning physical symptoms, psychological symptoms, functional abilities, and behaviors [16, 17], and the Fried Frailty Index (FFI), which addresses frailty as solely a physical phenotype (Table 3) [18]. Other scales, like the Groningen Frailty Indicator (GFI) and the Tilburg Frailty Indicator (TFI), are variants of these two approaches [47, 65]. Generally, not one tool is preferred over another, as each evaluates complementary aspects of the health and functional status of geriatric patients, which explains the wide prevalence of frailty in the systematic review by Collard et al. $[63,64,66]$.

Assessing frailty has importance in preparing patients for cancer treatments and radiotherapy. Frail patients are more likely than nonfrail patients to exhibit more side effects or have complications from both chemotherapeutic drugs and radiotherapy treatments and at the same time have less functional capacity with which to overcome these adverse effects. From one systematic review, it has been calculated that the median estimates of frailty and prefrailty in older patients with cancer are $42 \%$ (range 6\%-86\%) and $43 \%$ (range $13 \%-79 \%$ ), respectively [67]. Frailty was found to increase allcause mortality, postoperative mortality, postoperative complications, and treatment toxicities from procedural and/or chemotherapeutic interventions [67].

For a radiation oncologist, the construct of frailty in older patients can be considered a measure of functional reserve. In this context, patients identified as frail may be less likely to recover from radiation treatments compared to their younger counterparts. The radiation oncologist can consider 
Table 3: Phenotypic criteria for the Fried Frailty Index, adapted from [18].

\begin{tabular}{|c|c|}
\hline Characteristics of frailty & Criteria used to define frailty (from Fried et al.) \\
\hline Shrinking: weight loss (unintentional), sarcopenia (loss of muscle mass) & Baseline: $>10$ lbs lost unintentionally in prior year \\
\hline Weakness & Grip strength: lowest $20 \%$ (by gender, body mass index) \\
\hline Poor endurance; exhaustion & "Exhaustion" (self-reported) \\
\hline Slowness & Walking time/15 feet: slowest 20\% (by gender, height) \\
\hline Low activity & $\begin{array}{l}\text { Kcals/week: lowest } 20 \% \\
\text { (i) Males: }<383 \mathrm{Kcals} / \text { week } \\
\text { (ii) Females: }<270 \mathrm{Kcals} / \text { week }\end{array}$ \\
\hline
\end{tabular}

Presence of frailty

Positive for frailty phenotype: $\geq 3$ criteria present

Intermediate or prefrail: 1 or 2 criteria present

utilizing frailty to help better evaluate the older patient when planning their treatments. In a sample of older women with breast cancer, $26 \%$ had a baseline Fried frailty score $>1$ [68]. Radiotherapy-related fatigue was better predicted by the Fried frailty score than other assessments such as the Karnofsky Performance Status. A higher score on a Frailty Index modified to include the presence of comorbidities like diabetes and history of stroke was associated with significantly lower overall survival and other cause-specific survival in stage I/II non-small cell lung cancer patients who underwent stereotactic body radiation therapy (SBRT) [69].

Understanding the risks and toxicities associated with frailty during cancer treatments may help the older patient withstand and recover from the effects of chemotherapy and radiotherapy [70]. Frailty is a formal construct in geriatrics. In oncology, an analogous concept is that of functional reserve. Management of frailty relies first on its proper diagnosis and second on an understanding of how expected toxicities arising from cancer treatment might precipitate an event leading to an adverse outcome in a frail patient such as a fall (as in the case of the patient described in the above vignette). Several management options exist for health conditions and treatment complications that might result or get worse from frailty existing at baseline. These include pharmacologic interventions for sarcopenia, cachexia, and nutritional deficits [7173] and exercise interventions [74]. Overall, management should be multidisciplinary and involve physical therapists, dieticians, nurses, caregivers, geriatricians, oncologists, and radiation oncologists [75]. Understanding how frailty plays a role in the care of the older cancer patient allows us to more thoughtfully address how certain reduced capabilities might affect a person's tolerability of current cancer treatments.

\section{Special Radiation Treatment Considerations}

Radiotherapy is an important anticancer modality and sometimes the treatment of choice for patients regardless of age or comorbid condition (for example, prostate cancer). A decision to pursue radiotherapy requires a full comprehensive understanding of the goals of treatment, individual patient characteristics, and the predicted tolerability to the radiation treatment itself. An incomplete understanding of a patient's upfront ability to tolerate the effects of treatment may lead to interruption of treatment courses, which can lead to undesirable cancer repopulation [76, 77]. Clinicians may need to be extra careful of issues or problems that might arise during radiation treatment in the older individual. These include toxicities from radiation, treatment-related burdens persisting after radiation, and synergistically related toxicities resulting from combined chemoradiation.

5.1. Issues regarding the Biology of the Older Human Body. Older adults are susceptible to the same toxicities of radiation that affect their younger counterparts [78]. In general, radiation can cause irreversible damage to cells and tissues in the human body, resulting in acute injury manifesting a few weeks after radiation treatment, or long-term reduction in organ function manifesting months or years after [78]. Older adults, given their likelihood of having organs worse in function, are presumably more vulnerable to the toxicities of radiation therapy. Interestingly, in vitro studies have not shown whether age has any impact on the radiosensitivity of primary human cancers cells like fibroblasts, breast cancer cells, mucosa, and vascular smooth cells [79-82]. Clinically, there is evidence of worsening functional impairment in older patients treated with radiotherapy [78]. Some of the most concerning toxicities that older adults may have a higher vulnerability of experiencing are fatigue [83, 84], mucositis, xerostomia, dehydration, infections [78], and cognitive defects [85-88]. However, other studies have produced contradictory results regarding this subject [89-91]. There is continued controversy on whether a correlation exists between chronological age and incidence of radiation-related toxicities.

5.2. Increased Treatment Precision Can Reduce Toxicities. Over the years, advances in technology have led to radiation techniques that efficiently deliver adequate amount of radiation to an area with potential for reduced toxicity. Intensity-modulated radiation therapy (IMRT) and imageguided radiation treatment (IGRT) techniques allow the delivery of higher doses in the treatment volumes with better sparing of surrounding normal tissue [92]. These techniques have been associated with lower toxicities than other forms of radiation therapy in various types of cancers including cancer of the prostate, head and neck, breast, bladder, and rectum 
[93-97]. Stereotactic body radiation therapy (SBRT) allows for higher dosages to be delivered to a targeted tumor region with fewer numbers of fractions [98] and has been associated with a lower incidence of toxicities [99], such as radiation pneumonitis in NSCLC treatment for instance [100]. A recent study on brain metastases found that stereotactic radiosurgery (SRS) alone compared with SRS with whole brain RT can lead to a better conservation of cognitive ability and quality of life without compromising survival [101]. The advent of more precise radiation technologies has presented safer and efficient options of radiation that can be delivered to older patients with better toxicity profiles [94, 102-104].

Despite recent advances in precision technology, the functional status of older adults with physical impairments and/or comorbidities remains of utmost importance when considering the appropriate radiation treatment. Frailty can be a predictor of radiation-induced toxicity in older patients $[68,69]$. The presence of competing noncancer risk factors can negatively impact tolerance to radiotherapy. Women with breast cancer who also have a comorbid heart condition can be at higher risk of developing cardiotoxicity to radiotherapy treated to the breast [105].

Given their likelihood of experiencing increased toxicities, older adults are at risk of not being able to complete extended radiation treatments because of their amplified experience of side effects, decline in clinical status, or treatment burden regarding transport and financial costs [106, 107]. These patients would thereby benefit from hypofractionated treatment schedules, which deliver the same total doses as that of conventional schedules, but in a smaller number of treatment sessions (fewer visits to the treatment facility of hospital). There is also growing evidence that geriatric assessments may help with risk-stratifying patients receiving radiotherapy. One study found that a Vulnerable Elders Survey-13 (VES-13) score above 7 was associated with around 3 times greater probability for not completing a radiation treatment [108]. A prognostic index consisting of demographics, medication and hormone use, comorbidities, anxiety, and functional status was validated for patients with prostate cancer who underwent androgen deprivation therapy and/or radiation therapy [109]. Patients determined to be high-risk by the prognostic index had a significantly higher risk for fracture rate (19.2\% in derivation cohort, $16.5 \%$ in validation cohort).

5.3. Issues regarding Treatment-Related Burdens. Radiation treatments can negatively impact the quality of life for older adults in ways other than acute and long-term toxicities. As described above, older patients can be encumbered by geriatric syndromes that can reduce the effectiveness of anticancer treatments. Protocols and fractionation schedules that do not acknowledge the severity of these syndromes can subject older patients to treatment noncompliance and further deterioration in health.

The efficacy of radiation treatment lies in its successful delivery. To this end, patient cooperation throughout radiation treatment procedures is necessary. Presence of certain geriatric syndromes might affect a patient's ability to complete parts of the radiation treatment process [6].
For instance, patients with hearing impairments, highly prevalent among older adults, may not be able to promptly listen to directions during dynamic (e.g., respiratory motion management) protocols. Similarly, patients with dementia may not be able to verbalize sensations of discomfort or pain during radiation or remember instructions. Furthermore, patients with movement disorders like Parkinsonian tremors, or severe arthritis, may have difficulty with immobilization or positioning. Those with frailty or severe physical impairment may have difficulty accomplishing stressful maneuvers such as breath-holding or abdominal compression [102]. A focused evaluation of these potential issues upfront may allow workaround solutions to be developed that could make treatments less taxing and more manageable. Special accommodations may be made by treatment facilities or hospitals to make these techniques possible for patients with certain disabilities. For instance, respiratory motion management techniques can have visual or auditory guides (e.g., screens inside treatment rooms, special glasses, and sound alarms).

Over the past decade, newer approaches have been developed that can potentially address some of these technical challenges. Respiratory motion tracking allows for radiation to be delivered without the need for a breath hold [110]. However, these techniques tend to lengthen the treatment session time, which can increase patient discomfort (common in older patients, as previously mentioned). Four-dimensional computed tomography (4D-CT) and image guidance (4DIG) tracks organ movement over time through frequent image capture during the radiation course [111, 112]. Adaptive radiation therapy (ART) individualizes radiation treatment by replanning and redosing radiation daily, allowing for complicated patients who require varying treatment set-ups $[113,114]$.

Another important consideration must be made for the socioeconomic factors that often play a role in radiotherapy effectiveness in older adults. Extended fractionation schedules may require frequent travel between the radiotherapy facility and the patient's residence. Since older adults are vulnerable to treatment-related fatigue and deficits in physical activity, constant travel may severely impact their quality of life or may simply not be feasible [115-117].

In consideration of the socioeconomic factors and toxicities, older patients may fare better with shorter fractionation schedules without compromising tumor control. Hypofractionation has been studied to be an effective alternative to conservative fractionation in different cancers [118-120]. In breast cancer, older patients treated with hypofractionated RT (42.56 Gy in 16 fractions) as opposed to standard RT (50-60 Gy in 25-30 fractions) had 100\% overall survival and no severe toxicities or local recurrence at median followup of 15 months [120]. In glioblastoma multiforme (GBM), patients over 60 years of age receiving $40 \mathrm{~Gy}$ in 15 fractions over 3 weeks had similar overall survival to those who were treated with the standard $60 \mathrm{~Gy}$ course [121]. In head and neck cancer, patients with multiple comorbidities and overall poorer health may be able to tolerate split-course, accelerated, hypofractionated radiotherapy (SCAHRT), or a regimen comprising 60-72 Gy in 20-24 fractions with a break in the middle of the course [119]. 
Hypofractionated courses can also be useful in the palliative setting. For instance, in palliation of bone metastases, a lower incidence of acute toxicities (e.g., nausea and vomiting, diarrhea, and fatigue) was observed in $8 \mathrm{~Gy}$ in 1 fraction compared to $30 \mathrm{~Gy}$ in 10 fractions in some randomized trials [122].

However, hypofractionated courses may present with an additional inconvenience for older patients. Although the physical dose is lower, the dose per session is higher, which may lead to a higher likelihood of acute toxicities in normal tissues if the same tolerances used in normofractionated schedules are applied. It is important to emphasize the necessity of adjusting the dose constraints in hypofractionated schedules.

A reasonable alternative to delivering radiotherapy is omitting it in favor of more supportive measures. Supportive care alone may benefit some selected cancer patients [123]. However, caution must be made before making the decision to omit radiotherapy, as withholding adjuvant radiotherapy can risk tumor recurrence and worsening of tumor progression $[124,125]$.

5.4. Issues regarding Concurrent Chemoradiation Treatments. It has been shown that combined chemoradiation can improve survival in certain cancers, like that of head and neck, brain, endometrium, and lung [126-129]. However, chemotherapy adds toxicities that can compound those of radiation therapy, such as mucositis, cytopenia, and cardiotoxicity [130, 131]. In addition, because of their age-related reductions in kidney and liver function, older adults are prone to increased chemotherapy potency [6]. Evidence has shown that older individuals receiving combined chemoradiation treatments can experience amplified toxicities leading to more frequent hospitalizations and worse survival [132].

On the other hand, some trials have revealed that older patients may be able to tolerate chemoradiation for particular cancers similar to younger counterparts $[133,134]$. However, most of these trials only included older individuals who were medically fit and with few or no comorbidities [135]. Thus, results may not be routinely generalizable to patients with an increased number of comorbidities or functional impairments.

Toxicities may be better controlled by employing the use of more precise radiation technologies during chemoradiation. Chemoradiotherapy using IMRT for treatment of cervical cancer has been shown to limit spread of radiation to the bone marrow and reduce incidence of hematologic toxicity [136]. Use of tomotherapy-based IGRT in chemoradiation for small cell lung cancer was associated with no grades 3 to 4 pneumonitis, although other toxicities like esophagitis and pulmonary embolism was still observed in some patients [137].

Combining chemotherapy with hypofractionated radiation may be feasible without increasing overall toxicity. A retrospective analysis examining the concurrent use of temozolomide (TMZ) and radiotherapy in glioblastoma found that older patients receiving hypofractionation and TMZ generally tolerated the combined regimen well [138].
Older adults with poorer functional status may better tolerate sequential, rather than concurrent, chemoradiation [139]. One study found that patients with nasopharyngeal carcinoma receiving sequential chemoradiation had overall less severe acute toxicities (leukopenia, anemia, mucositis, and weight loss) than those who underwent concurrent chemoradiotherapy; however, there was no significant difference in survival between the two modalities [140]. The use of more precise radiation technologies, hypofractionation, and sequential chemoradiation may benefit older individuals with poor functional status.

\section{A Framework for Making Management Decisions}

A central question is how to best utilize the skillset of specialty-level geriatrics to optimize cancer treatment for older patients. A conceptual model utilizing four domains (tumor behavior, noncancer related competing risks, functional reserve, and palliative needs) described by G. L. Smith and B. D. Smith can be considered a foundation for making tailored radiation treatment plans [141]. A comprehensive geriatric assessment and other abbreviated, easy-to-use geriatric assessment screening tools augment this model by facilitating ascertainment of objective data about competing health risks and functional reserve $[8,54]$. Routine use of these assessment tools in practice may help risk-stratify geriatric patients and guide treatment decision-making. An objective and complete assessment of an older patient may uncover potentially modifiable geriatric impairments. These in turn might affect the choice of radiation treatment modality, set-up, technique, dose, and fractionation that would be most appropriate based upon an individual's unique set of clinical characteristics and circumstances [50, 51, 53, 67]. At the same time, a full geriatric assessment may be timeconsuming and resource intensive [41]. Not every cancer clinician may be trained to perform one, and not every older individual may require one. Additional studies are needed to find reliable, routine, and easy-to-use screening tools for radiation oncologists' use that can expedite assessment [41, 142].

Choosing the "best" radiotherapy plan for the older adult requires clinical judgment and acknowledgment of patient preferences and concerns. Quality of life and functional independence may be highly valued among older adults with cancer. At the same time, undergoing radiotherapy, like any other anticancer treatments, can be an arduous endeavor and may be associated with temporary or permanent detriments in quality of life and function that persist and even worsen at times after treatment is over. An upfront discussion of the potential risks, benefits, and acceptable trade-offs of treatment can be more thoroughly and clearly conducted by recognizing the multidimensional factors in caring for the older adult and screening for geriatric impairments that might directly impact a patient's treatment outcome. It may be reasonable in many instances to involve extra supportive services earlier in a treatment course for older adults at higher risk (e.g., significant comorbidities and frailty, or for whom cancer treatments may be particularly burdensome). 
These might include supportive oncology specialists whose role is to add a layer of support for both patients and caregivers. This type of care may be delivered by palliative care clinicians whose role is to care for any type of cancer patient regardless of cancer type, stage, intent of treatment, or age. Incorporating supportive oncology specialists earlier in the management of cancer patients is associated with better patient-reported quality of life in multiple domains [143].

It is important for radiation oncologists to recognize the limitations that their older patients may have in terms of completing radiation treatment courses. Many patients may experience treatment interruptions for a variety of reasons (toxicity-related, patient-related, caregiver-related, treatment machine-related, etc.). The efficacy of the treatment, however, depends upon it being completed with minimal interruptions $[76,77]$. Thus, radiation oncologists may keep this in mind as they make recommendations during consultation and counsel their patients during on-treatment visits in order to prevent and/or reduce these interruptions as much as possible. By bringing specific mention to the potentially harmful effects that many interruptions can cause, radiation oncologists and patients/caregivers can decide together what treatment regimens are most appropriate.

The data gathered from a geriatric assessment allows radiation oncologists to deepen their understanding of potential treatment implications for older patients in a way that can facilitate better informed shared decision-making. A multidisciplinary supportive care approach involving geriatric expertise, social work services, visiting nurse assistance, nutritional support, physical therapy, and others can be employed in a timely manner, possibly preventing a consequence of treatment such as that described in the introductory vignette. Supportive services may also include individuals specializing in psychosocial oncology [144]. Attention to psychosocial health is a critical aspect of comprehensive supportive care for cancer patients of all ages.

\section{Conclusion}

The overall approach to delivering any cancer treatment for the geriatric patient, whether it consists of surgery, chemotherapy, radiotherapy, or the combination of these, requires a global understanding of physical, functional, and social well-being. Assessment tools are available for more optimal evaluation of older individuals with cancer. Integrating abbreviated versions of these tools is feasible to do within the routine flow of a radiation oncology clinic. The decision to pursue specific treatments requires patientcentered communication of preferences, concerns, risks, and benefits among patients, caregivers, and clinicians.

\section{Conflicts of Interest}

The authors declare that they have no conflicts of interest.

\section{Acknowledgments}

This work is supported by a grant from the Claude D. Pepper Older Americans Independence Center at the National Institute of Aging/National Institutes of Health (KVD, NG, SC) (no. 5P30AG028741), a career development grant from the National Palliative Care Research Center (KVD), and a seed grant from the American Medical Association Foundation (SC).

\section{References}

[1] J. Bourhis, J. Overgaard, H. Audry et al., "Hyperfractionated or accelerated radiotherapy in head and neck cancer: a metaanalysis," The Lancet, vol. 368, no. 9538, pp. 843-854, 2006.

[2] Federal Interagency Forum on Aging-Related Statistics. Older Americans 2016: Key indicators of well-being. Federal Interagency Forum on Aging-Related Statistics. Washington, DC: U.S. Government Printing Office. pp. 82-83, 116, 135, 2016.

[3] B. D. Smith, G. L. Smith, A. Hurria, G. N. Hortobagyi, and T. A. Buchholz, "Future of cancer incidence in the United States: burdens upon an aging, changing nation," Journal of Clinical Oncology, vol. 27, no. 17, pp. 2758-2765, 2009.

[4] B. D. Smith, B. G. Haffty, L. D. Wilson, G. L. Smith, A. N. Patel, and T. A. Buchholz, "The future of radiation oncology in the United States from 2010 to 2020: Will supply keep pace with demand?" Journal of Clinical Oncology, vol. 28, no. 35, pp. 5160$5165,2010$.

[5] K. J. Anstey, S. R. Lord, and G. A. Smith, "Measuring human functional age: A review of empirical findings," Experimental Aging Research, vol. 22, no. 3, pp. 245-266, 1996.

[6] W. R. Hazzard and J. B. Halter, Hazzard's Geriatric Medicine and Gerontology, McGraw-Hill Medical, New York, NY, USA, 6th edition, 2009.

[7] Centers for Medicare and Medicaid Services, Chronic Conditions among Medicare Beneficiaries, Chartbook, 2012 Edition, vol. 11, Baltimore, MD, USA, 2012.

[8] S. Jiang and P. Li, "Current development in elderly comprehensive assessment and research methods," BioMed Research International, vol. 2016, Article ID 3528248, 10 pages, 2016.

[9] P. Szturz and J. B. Vermorken, "Treatment of elderly patients with squamous cell carcinoma of the head and neck," Frontiers in Oncology, vol. 6, article 199, 2016.

[10] M. Charlson, T. P. Szatrowski, J. Peterson, and J. Gold, "Validation of a combined comorbidity index," Journal of Clinical Epidemiology, vol. 47, no. 11, pp. 1245-1251, 1994.

[11] B. S. Linn, M. W. Linn, and L. Gurel, "Cumulative illness rating scale," Journal of the American Geriatrics Society, vol. 16, no. 5, pp. 622-626, 1968.

[12] A. S. Detsky, J. R. McLaughlin, J. P. Baker et al., "What is subjective global assessment of nutritional status?" Journal of Parenteral and Enteral Nutrition, vol. 11, no. 1, pp. 8-13, 1987.

[13] Y. Guigoz, B. Vellas, and P. J. Garry, "Assessing the nutritional status of the elderly: the Mini Nutritional Assessment as part of the geriatric evaluation," Nutrition Reviews, vol. 54, no. 1, pp. S59-S65, 1996.

[14] O. Bouillanne, G. Morineau, and C. Dupont, "Geriatric Nutritional Risk Index: a new index for evaluating at-risk elderly medical patients," The American Journal of Clinical Nutrition, vol. 82, pp. 777-783, 2005. 
[15] American Geriatrics Society 2015 Beers Criteria Update Expert Panel, "American Geriatrics Society 2015 updated beers criteria for potentially inappropriate medication use in older adults," Journal of the American Geriatrics Society, vol. 63, pp. 22272246, 2015.

[16] K. Rockwood and A. Mitnitski, "Frailty Defined by Deficit Accumulation and Geriatric Medicine Defined by Frailty," Clinics in Geriatric Medicine, vol. 27, no. 1, pp. 17-26, 2011.

[17] A. B. Mitnitski, X. Song, and K. Rockwood, "The estimation of relative fitness and frailty in community-dwelling older adults using self-report data," The Journals of Gerontology. Series A, Biological Sciences and Medical Sciences, vol. 59, no. 6, pp. M627M632, 2004.

[18] L. P. Fried, C. M. Tangen, J. Walston et al., "Frailty in older adults: evidence for a phenotype," The Journals of Gerontology. Series A, Biological Sciences and Medical Sciences, vol. 56, no. 3, pp. M146-M156, 2001.

[19] D. Saliba, M. Elliott, L. Z. Rubenstein et al., "The vulnerable elders survey: a tool for identifying vulnerable older people in the community," Journal of the American Geriatrics Society, vol. 49, no. 12, pp. 1691-1699, 2001.

[20] F. I. Mahoney and D. W. Barthel, "Functional evaluation: the Barthel Index," Maryland State Medical Journal, vol. 14, pp. 6165, 1965.

[21] S. Katz, A. B. Ford, R. W. Moskowitz, B. A. Jackson, and M. W. Jaffe, "Studies of illness in the aged. the index of adl: a standardized measure of biological and psychosocial function," Journal of the American Medical Association, vol. 185, pp. 914919, 1963.

[22] R. I. Pfeffer, T. T. Kurosaki, C. H. Harrah, J. M. Chance, and S. Filos, "Measurement of functional activities in older adults in the community," Journal of Gerontology, vol. 37, no. 3, pp. 323329,1982 .

[23] M. W. Linn and B. S. Linn, "The rapid disability rating scale2," Journal of the American Geriatrics Society, vol. 30, no. 6, pp. 378-382, 1982.

[24] Y. Lajoie and S. P. Gallagher, "Predicting falls within the elderly community: comparison of postural sway, reaction time, the Berg balance scale and the Activities-specific Balance Confidence (ABC) scale for comparing fallers and non-fallers," Archives of Gerontology and Geriatrics, vol. 38, no. 1, pp. 11-26, 2004.

[25] D. Podsiadlo and S. Richardson, “The Timed Up \& Go: a test of basic functional mobility for frail elderly persons," Journal of the American Geriatrics Society, vol. 39, pp. 142-148, 1991.

[26] M. E. Tinetti, "Performance-oriented assessment of mobility problems in elderly patients," Journal of the American Geriatrics Society, vol. 34, no. 2, pp. 119-126, 1986.

[27] R. Jester, S. Wade, and K. Henderson, "A pilot investigation of the efficacy of falls risk assessment tools and prevention strategies in an elderly hip fracture population," Journal of Orthopaedic Nursing, vol. 9, no. 1, pp. 27-34, 2005.

[28] E. Olsson, B. Löfgren, Y. Gustafson, and L. Nyberg, "Validation of a fall risk index in stroke rehabilitation," Journal of Stroke and Cerebrovascular Diseases, vol. 14, no. 1, pp. 23-28, 2005.

[29] E. Stone, M. Skubic, M. Rantz, C. Abbott, and S. Miller, "Average in-home gait speed: investigation of a new metric for mobility and fall risk assessment of elders," Gait \& Posture, vol. 41, no. 1, pp. 57-62, 2015.

[30] I. Bautmans and T. Mets, "A fatigue resistance test for elderly persons based on grip strength: Reliability and comparison with healthy young subjects," Aging Clinical and Experimental Research, vol. 17, no. 3, pp. 217-222, 2005.

[31] T. N. Tombaugh and N. J. McIntyre, "The mini-mental state examination: a comprehensive review," Journal of the American Geriatrics Society, vol. 40, no. 9, pp. 922-935, 1992.

[32] Z. S. Nasreddine, N. A. Phillips, V. Bédirian et al., "The Montreal Cognitive Assessment, MoCA: a brief screening tool for mild cognitive impairment," Journal of the American Geriatrics Society, vol. 53, no. 4, pp. 695-699, 2005.

[33] A. F. Jorm, "The Informant Questionnaire on cognitive decline in the elderly (IQCODE): a review," International Psychogeriatrics, vol. 16, no. 3, pp. 275-293, 2004.

[34] J. A. Yesavage, T. L. Brink, T. L. Rose et al., "Development and validation of a geriatric depression screening scale: A preliminary report," Journal of Psychiatric Research, vol. 17, no. 1, pp. 37-49, 1982.

[35] S. A. Greenberg, "How To try this: the geriatric depression scale: short form," AJN, American Journal of Nursing, vol. 107, no. 10, pp. 60-69, 2007.

[36] M. Hamilton, "A rating scale for depression," Journal of Neurology, Neurosurgery \& Psychiatry, vol. 23, pp. 56-62, 1960.

[37] N. A. Pachana, G. J. Byrne, H. Siddle, N. Koloski, E. Harley, and E. Arnold, "Development and validation of the geriatric anxiety inventory," International Psychogeriatrics, vol. 19, no. 1, pp. 103$114,2007$.

[38] D. L. Segal, A. June, M. Payne, F. L. Coolidge, and B. Yochim, "Development and initial validation of a self-report assessment tool for anxiety among older adults: the Geriatric Anxiety Scale," Journal of Anxiety Disorders, vol. 24, no. 7, pp. 709-714, 2010.

[39] A. S. Zigmond and R. P. Snaith, "The hospital anxiety and depression scale," Acta Psychiatrica Scandinavica, vol. 67, no. 6, pp. 361-370, 1983.

[40] A. Moser, A. E. Stuck, R. A. Silliman, P. A. Ganz, and K. M. Clough-Gorr, "The eight-item modified Medical Outcomes Study Social Support Survey: Psychometric evaluation showed excellent performance," Journal of Clinical Epidemiology, vol. 65, no. 10, pp. 1107-1116, 2012.

[41] L. Decoster, K. Van Puyvelde, S. Mohile et al., "Screening tools for multidimensional health problems warranting a geriatric assessment in older cancer patients: An update on SIOG recommendations," Annals of Oncology, vol. 26, no. 2, pp. 288300, 2015.

[42] C. A. Bellera, M. Rainfray, S. Mathoulin-Pélissier et al., "Screening older cancer patients: First evaluation of the G-8 geriatric screening tool," Annals of Oncology, vol. 23, no. 8, pp. 2166-2172, 2012.

[43] C. Kenis, K. Milisen, J. Flamaing et al., "Performance of two geriatric screening tools in older patients with cancer," Journal of Clinical Oncology, vol. 32, no. 1, pp. 19-26, 2014.

[44] S. W. Meldon, L. C. Mion, R. M. Palmer et al., "A brief riskstratification tool to predict repeat emergency department visits and hospitalizations in older patients discharged from the emergency department," Academic Emergency Medicine, vol. 10, no. 3, pp. 224-232, 2003.

[45] K. E. Ensrud, S. K. Ewing, B. C. Taylor et al., "Comparison of 2 frailty indexes for prediction of falls, disability, fractures, and death in older women," JAMA Internal Medicine, vol. 168, no. 4, pp. 382-389, 2008.

[46] K. E. Ensrud, S. K. Ewing, P. M. Cawthon et al., "A comparison of frailty indexes for the prediction of falls, disability, fractures, 
and mortality in older men," Journal of the American Geriatrics Society, vol. 57, no. 3, pp. 492-498, 2009.

[47] I. Drubbel, N. Bleijenberg, G. Kranenburg et al., "Identifying frailty: Do the Frailty Index and Groningen Frailty Indicator cover different clinical perspectives? a cross-sectional study," BMC Family Practice, vol. 14, article 64, 2013.

[48] J. A. Overcash, J. Beckstead, M. Extermann, and S. Cobb, “The abbreviated comprehensive geriatric assessment (aCGA): A retrospective analysis," Critical Review in Oncology/Hematology, vol. 54, no. 2, pp. 129-136, 2005.

[49] D. A. Matthews, "Dr. Marjory Warren and the Origin of British Geriatrics," Journal of the American Geriatrics Society, vol. 32, no. 4, pp. 253-258, 1984.

[50] A. Stotter, M. W. Reed, L. J. Gray, N. Moore, and T. G. Robinson, "Comprehensive Geriatric Assessment and predicted 3-year survival in treatment planning for frail patients with early breast cancer," British Journal of Surgery, vol. 102, no. 5, pp. 525-533, 2015.

[51] N. Ommundsen, T. B. Wyller, A. Nesbakken et al., "Frailty is an independent predictor of survival in older patients with colorectal cancer," The Oncologist, vol. 19, no. 12, pp. 1268-1275, 2014.

[52] R. Corre, L. Greillier, H. Le Caer et al., "Use of a comprehensive geriatric assessment for the management of elderly patients with advanced non-small-cell lung cancer: The phase III randomized ESOGIA-GFPC-GECP 08-02 study," Journal of Clinical Oncology, vol. 34, pp. 1476-1483, 2016.

[53] S. Ulger, M. C. Kizilarslanoglu, M. K. Kilic et al., "Estimating radiation therapy toxicity and tolerability with comprehensive assessment parameters in geriatric cancer patients," Asian Pacific Journal of Cancer Prevention, vol. 16, no. 5, pp. 1965-1969, 2015.

[54] P. Chaïbi, N. Magné, S. Breton et al., "Influence of geriatric consultation with comprehensive geriatric assessment on final therapeutic decision in elderly cancer patients," Critical Review in Oncology/Hematology, vol. 79, no. 3, pp. 302-307, 2011.

[55] S. G. Mohile, C. Velarde, A. Hurria et al., "Geriatric assessmentguided care processes for older adults: a delphi consensus of geriatric oncology experts," Journal of the National Comprehensive Cancer Network, vol. 13, no. 9, pp. 1120-1130, 2015.

[56] NK. Aaronson, S. Ahmedzai, and B. Bergman, “The European Organisation for Research and Treatment of Cancer QLQ-C30: a quality-of-life instrument for use in international clinical trials in oncology," Journal of the National Cancer Institute, vol. 85, pp. 365-376, 1993.

[57] S. Wheelwright, A.-S. Darlington, D. Fitzsimmons et al., "International validation of the EORTC QLQ-ELD14 questionnaire for assessment of health-related quality of life elderly patients with cancer," British Journal of Cancer, vol. 109, no. 4, pp. 852858,2013

[58] A. Clegg, J. Young, S. Iliffe, M. O. Rikkert, and K. Rockwood, "Frailty in elderly people," The Lancet, vol. 381, no. 9868, pp. 752-762, 2013.

[59] J. E. Morley, B. Vellas, G. Abellan van Kan et al., "Frailty consensus: a call to action," Journal of the American Medical Directors Association, vol. 14, no. 6, pp. 392-397, 2013.

[60] N. M. de Vries, J. B. Staal, C. D. van Ravensberg, J. S. M. Hobbelen, M. G. M. Olde Rikkerte, and M. W. G. van der Nijhuis-Sanden, "Outcome instruments to measure frailty: a systematic review," Ageing Research Reviews, vol. 10, pp. 104-114, 2011.
[61] F. Buckinx, Y. Rolland, J.-Y. Reginster, C. Ricour, J. Petermans, and O. Bruyère, "Burden of frailty in the elderly population: Perspectives for a public health challenge," Archives of Public Health, vol. 73, no. 1, article 19, 2015.

[62] R. J. Gobbens, K. G. Luijkx, M. T. Wijnen-Sponselee, and J. M. Schols, "Toward a conceptual definition of frail community dwelling older people," Nursing Outlook, vol. 58, no. 2, pp. 76$86,2010$.

[63] R. M. Collard, H. Boter, R. A. Schoevers, and R. C. Oude Voshaar, "Prevalence of frailty in community-dwelling older persons: a systematic review," Journal of the American Geriatrics Society, vol. 60, no. 8, pp. 1487-1492, 2012.

[64] O. Theou, T. D. Brothers, A. Mitnitski, and K. Rockwood, "Operationalization of frailty using eight commonly used scales and comparison of their ability to predict all-cause mortality," Journal of the American Geriatrics Society, vol. 61, no. 9, pp. 15371551, 2013.

[65] R. J. J. Gobbens, M. A. L. M. van Assen, K. G. Luijkx, M. T. Wijnen-Sponselee, and J. M. G. A. Schols, "The tilburg frailty indicator: psychometric properties," Journal of the American Medical Directors Association, vol. 11, no. 5, pp. 344-355, 2010.

[66] M. Cesari, G. Gambassi, G. A. Van Kan, and B. Vellas, "The frailty phenotype and the frailty index: different instruments for different purposes," Age and Ageing, vol. 43, no. 1, pp. 10-12, 2014.

[67] C. Handforth, A. Clegg, C. Young et al., "The prevalence and outcomes of frailty in older cancer patients: a systematic review," Annals of Oncology, vol. 26, no. 6, pp. 1091-1101, 2015.

[68] M. D. Denkinger, M. Hasch, A. Gerstmayer, R. Kreienberg, T. Nikolaus, and K. Hancke, "Predicting fatigue in older breast cancer patients receiving radiotherapy: A head-to-head comparison of established assessments," Zeitschrift für Gerontologie und Geriatrie, vol. 48, no. 2, pp. 128-134, 2015.

[69] I. Franco, J. Romano, F. Chipidza et al., "Modified Frailty Index as a Predictor of Overall and Other Cause-Specific Survival in Early-Stage Non-Small Cell Lung Cancer Patients Treated With Stereotactic Body Radiation Therapy," International Journal of Radiation Oncology • Biology • Physics, vol. 96, no. 2, pp. E449E450, 2016.

[70] M. Huisingh-Scheetz and J. Walston, "How should older adults with cancer be evaluated for frailty?" Journal of Geriatric Oncology, vol. 8, no. 1, pp. 8-15, 2017.

[71] H. M. Holmes, M. S. Beck, and J. H. Rowe, "Geriatrics: Year in review, Journal of Geriatric Oncology, vol. 7, no. 5, pp. 404-408, 2016.

[72] M. Cesari, R. Fielding, O. Benichou et al., "harmacological interventions in frailty and sarcopenia: report by the International Conference on Frailty and Sarcopenia Research task force," Journal of Frailty Aging, vol. 4, pp. 114-120, 2015.

[73] K. Takayama, N. Katakami, T. Yokoyama et al., "Anamorelin (ONO-7643) in Japanese patients with non-small cell lung cancer and cachexia: results of a randomized phase 2 trial," Supportive Care in Cancer, vol. 24, no. 8, pp. 3495-3505, 2016.

[74] M. Giné-Garriga, M. Roqué-Fíguls, L. Coll-Planas, M. SitjàRabert, and A. Salvà, "Physical exercise interventions for improving performance-based measures of physical function in community-dwelling, frail older adults: a systematic review and meta-analysis," Archives of Physical Medicine and Rehabilitation, vol. 95, no. 4, pp. 753-769, 2014.

[75] I. D. Cameron, N. Fairhall, C. Langron et al., "A multifactorial interdisciplinary intervention reduces frailty in older people: randomized trial," BMC Medicine, vol. 11, no. 1, article 65, 2013. 
[76] J. J. Kim and I. F. Tannock, "Repopulation of cancer cells during therapy: an important cause of treatment failure," Nature Reviews Cancer, vol. 5, no. 7, pp. 516-525, 2005.

[77] E. J. Hall and A. J. Giaccia, Radiobiology for the Radiologist, Lippincott Williams \& Wilkins, Philadelphia, PA, USA, 7th edition, 2012.

[78] J. Gomez-Millan, "Radiation therapy in the elderly: More side effects and complications?" Critical Review in Oncology/ Hematology, vol. 71, no. 1, pp. 70-78, 2009.

[79] A. Baeyens, R. Van Den Broecke, A. Makar et al., "Chromosomal radiosensitivity in breast cancer patients: influence of age of onset of the disease," Oncology Reports, vol. 13, pp. 347-353, 2005.

[80] W. Landuyt and E. Van der Schueren, "Effect of age on the radiation-induced repopulation in mouse lip mucosa," Strahlentherapie und Onkologie, vol. 167, pp. 41-45, 1991.

[81] E. M. Rosen, I. D. Goldberg, K. V. Myrick, and S. E. Levenson, "Radiation survival of vascular smooth muscle cells as a function of age," International Journal of Radiation Biology and Related Studies in Physics, Chemistry and Medicine, vol. 48, no. 1, pp. 71-79, 1985.

[82] V. Rudat, A. Dietz, C. Conradt, K.-J. Weber, and M. Flentje, "In vitro radiosensitivity of primary human fibroblasts. Lack of correlation with acute radiation toxicity in patients with head and neck cancer," Radiotherapy \& Oncology, vol. 43, no. 2, pp. 181-188, 1997.

[83] B. A. Jereczek-Fossa, H. R. Marsiglia, and R. Orecchia, "Radiotherapy-related fatigue," Critical Review in Oncology/ Hematology, vol. 41, no. 3, pp. 317-325, 2002.

[84] X. S. Wang and J. F. Woodruff, "Cancer-related and treatmentrelated fatigue," Gynecologic Oncology, vol. 136, no. 3, pp. 446452, 2015.

[85] A. Asai, M. Matsutani, and T. Kohno, "Subacute brain atrophy after radiation therapy for malignant brain tumor," Cancer, vol. 63, pp. 1962-1974, 1989.

[86] J. R. Crossen, D. Garwood, E. Glatstein, and E. A. Neuwelt, "Neurobehavioral sequelae of cranial irradiation in adults: a review of radiation-induced encephalopathy," Journal of Clinical Oncology, vol. 12, no. 3, pp. 627-642, 1994.

[87] J. P. Maire, B. Coudin, J. Guérin, and M. Caudry, "Neuropsychologic Impairment in Adults with Brain Tumors," American Journal of Clinical Oncology, vol. 10, no. 2, pp. 156-162, 1987.

[88] L. A. Stylopoulos, A. E. George, and M. J. de Leon, "Longitudinal CT study of parenchymal brain changes in glioma survivors," American Journal of Neuroradiology, vol. 9, pp. 517-522, 1988.

[89] J. S. Grubey, Y. Raji, W. S. Duke, and D. J. Terris, "Outpatient thyroidectomy is safe in the elderly and super-elderly," The Laryngoscope, 2017.

[90] M. C. Ward, C. A. Reddy, D. J. Adelstein, and S. A. Koyfman, "Use of systemic therapy with definitive radiotherapy for elderly patients with head and neck cancer: A National Cancer Data Base analysis," Cancer, vol. 122, no. 22, pp. 3472-3483, 2016.

[91] T. Pignon, J.-C. Horiot, W. Van Den Bogaert, M. Van Glabbeke, and P. Scalliet, "No age limit for radical radiotherapy in head and neck tumours," European Journal of Cancer Part A: General Topics, vol. 32, no. 12, pp. 2075-2081, 1996.

[92] R. K. Ten Haken and T. S. Lawrence, "The clinical application of intensity-modulated radiation therapy," Seminars in Radiation Oncology, vol. 16, no. 4, pp. 224-231, 2006.

[93] G. Ghosh, R. Tallari, and A. Malviya, "Toxicity profile of IMRT vs $3 \mathrm{D}-\mathrm{CRT}$ in head and neck cancer: A retrospective study,"
Journal of Clinical and Diagnostic Research, vol. 10, no. 9, pp. XC01-XC03, 2016.

[94] L. J. Lutkenhaus, R. M. van Os, A. Bel, and M. C. C. M. Hulshof, "Clinical results of conformal versus intensity-modulated radiotherapy using a focal simultaneous boost for muscleinvasive bladder cancer in elderly or medically unfit patients," Journal of Radiation Oncology, vol. 11, no. 1, article 45, 2016.

[95] S. Y. Ng, K. L. Colborn, L. Cambridge et al., "Acute toxicity with intensity modulated radiotherapy versus 3-dimensional conformal radiotherapy during preoperative chemoradiation for locally advanced rectal cancer," Radiotherapy \& Oncology, vol. 121, no. 2, pp. 252-257, 2016.

[96] J.-F. Yang, M.-S. Lee, C.-S. Lin et al., "Long-term breast cancer patient outcomes after adjuvant radiotherapy using intensitymodulated radiotherapy or conventional tangential radiotherapy," Medicine, vol. 95, no. 11, article e3113, 2016.

[97] H. Yamazaki, S. Nakamura, T. Nishimura et al., "Transitioning from conventional radiotherapy to intensity-modulated radiotherapy for localized prostate cancer: Changing focus from rectal bleeding to detailed quality of life analysis," Journal of Radiation Research, vol. 55, no. 6, pp. 1033-1047, 2014.

[98] B. K. Chang and R. D. Timmerman, "Stereotactic Body Radiation Therapy," American Journal of Clinical Oncology, vol. 30, no. 6, pp. 637-644, 2007.

[99] A. Amini, J. D. McDermott, G. Gan et al., "Stereotactic body radiotherapy as primary therapy for head and neck cancer in the elderly or patients with poor performance," Frontiers in Oncology, vol. 4, no. 274, 2014.

[100] J. Nyman, A. Hallqvist, J. A. Lund et al., "SPACE - a randomized study of SBRT vs conventional fractionated radiotherapy in medically inoperable stage I NSCLC," Radiotherapy \& Oncology, vol. 121, no. 1, pp. 1-8, 2016.

[101] P. D. Brown, K. Jaeckle, K. V. Ballman et al., "Effect of radiosurgery alone vs radiosurgery with whole brain radiation therapy on cognitive function in patients with 1 to 3 brain metastases a randomized clinical trial," Journal of the American Medical Association, vol. 316, no. 4, pp. 401-409, 2016.

[102] I. H. Kunkler, R. Audisio, Y. Belkacemi et al., "Review of current best practice and priorities for research in radiation oncology for elderly patients with cancer: The international society of geriatric oncology (SIOG) task force," Annals of Oncology, vol. 25, no. 11, 2014.

[103] M. L. Brown, C. Glanzmann, G. Huber, M. Bredell, T. Rordorf, and G. Studer, "IMRT/VMAT for malignancies in the headand-neck region: Outcome in patients aged 80+," Strahlentherapie und Onkologie, vol. 192, no. 8, pp. 526-536, 2016.

[104] S. H. Lin, N. Zhang, J. Godby et al., "Radiation modality use and cardiopulmonary mortality risk in elderly patients with esophageal cancer," Cancer, vol. 122, no. 6, pp. 917-928, 2016.

[105] S. C. Darby, M. Ewertz, P. McGale et al., "Risk of ischemic heart disease in women after radiotherapy for breast cancer," The New England Journal of Medicine, vol. 368, no. 11, pp. 987-998, 2013.

[106] J. Horiot, "Radiation Therapy and the Geriatric Oncology Patient," Journal of Clinical Oncology, vol. 25, no. 14, pp. 19301935, 2007.

[107] M. D. Fesinmeyer, V. Mehta, L. Tock, D. Blough, C. McDermott, and S. D. Ramsey, "Completion of radiotherapy for local and regional head and neck cancer in medicare," Archives of Otolaryngology-Head and Neck Surgery, vol. 135, no. 9, pp. 860-867, 2009.

[108] D. Spyropoulou, A. G. Pallis, M. Leotsinidis, and D. Kardamakis, "Completion of radiotherapy is associated with the 
Vulnerable Elders Survey-13 score in elderly patients with cancer," Journal of Geriatric Oncology, vol. 5, no. 1, pp. 20-25, 2014.

[109] T. R. Graham-Steed, P. R. Soulos, N. Dearing, J. Concato, M. E. Tinetti, and C. P. Gross, "Development and validation of a prognostic index for fracture risk in older men undergoing prostate cancer treatment," Journal of Geriatric Oncology, vol. 5, no. 4, pp. 343-351, 2014.

[110] S. S. Korreman, A. N. Pedersen, T. J. Nøttrup, L. Specht, and H. Nyström, "Breathing adapted radiotherapy for breast cancer: Comparison of free breathing gating with the breathhold technique," Radiotherapy \& Oncology, vol. 76, no. 3, pp. 311-318, 2005.

[111] S. S. Korreman, "Image-guided radiotherapy and motion management in lung cancer," British Journal of Radiology, vol. 88, no. 1051, article 20150100, 2015.

[112] S. Korreman, G. Persson, D. Nygaard, C. Brink, and T. JuhlerNøttrup, "Respiration-correlated image guidance is the most important radiotherapy motion management strategy for most lung cancer patients," International Journal of Radiation Oncology • Biology • Physics, vol. 83, no. 4, pp. 1338-1343, 2012.

[113] P. H. Ahn, C.-C. Chen, A. I. Ahn et al., "Adaptive planning in intensity-modulated radiation therapy for head and neck cancers: single-institution experience and clinical implications," International Journal of Radiation Oncology • Biology • Physics, vol. 80, no. 3, pp. 677-685, 2011.

[114] D. L. Schwartz, A. S. Garden, and S. J. Shah, "Adaptive radiotherapy for head and neck cancer-dosimetric results from a prospective clinical trial," Radiotherapy \& Oncology, vol. 106, pp. 80-84, 2013.

[115] C. Miaskowski, S. M. Paul, B. A. Cooper et al., "Trajectories of fatigue in men with prostate cancer before, during, and after radiation therapy," Journal of Pain and Symptom Management, vol. 35, no. 6, pp. 632-643, 2008.

[116] A. Dhruva, M. Dodd, S. M. Paul et al., “Trajectories of Fatigue in Patients With Breast Cancer Before, During, and After Radiation Therapy," Cancer Nursing, vol. 33, no. 3, pp. 201-212, 2010.

[117] G. Karthikeyan, D. Jumnani, R. Prabhu, U. K. Manoor, and S. S. Supe, "Prevalence of fatigue among cancer patients receiving various anticancer therapies and its impact on Quality of Life: A cross-sectional study," Indian Journal of Palliative Care, vol. 18, no. 3, pp. 165-175, 2012.

[118] B. Méry, A. T. Falk, A. Assouline et al., "Hypofractionated radiation therapy for treatment of bladder carcinoma in patients aged 90 years and more: A new paradigm to be explored?" International Urology and Nephrology, vol. 47, no. 7, pp. 11291134, 2015.

[119] T. J. Bledsoe, A. R. Noble, C. A. Reddy et al., "Split-course accelerated hypofractionated radiotherapy (SCAHRT): A safe and effective option for head and neck cancer in the elderly or infirm," Anticancer Research, vol. 36, no. 3, pp. 933-940, 2016.

[120] F. M. Giugliano, S. Falivene, E. Esposito et al., "Short-course radiotherapy in elderly women with breast cancer: Comparison by age, comorbidity index and toxicity," International Journal of Surgery, vol. 33, pp. S92-S96, 2016.

[121] W. Roa, P. M. A. Brasher, G. Bauman et al., "Abbreviated course of radiation therapy in older patients with glioblastoma multiforme: A prospective randomized clinical trial," Journal of Clinical Oncology, vol. 22, no. 9, pp. 1583-1588, 2004.

[122] E. Chow, L. Zeng, N. Salvo, K. Dennis, M. Tsao, and S. Lutz, "Update on the systematic review of palliative radiotherapy trials for bone metastases," Clinical Oncology, vol. 24, no. 2, pp. 112-124, 2012.

[123] J. N. Evers, S. E. Schild, B. Segedin et al., "A new score predicting survival prognosis after whole-brain radiotherapy alone for brain metastases in elderly patients," Anticancer Research, vol. 34, no. 5, pp. 2455-2458, 2014.

[124] G. Martelli, P. Boracchi, E. Guzzetti et al., "Omission of radiotherapy in elderly patients with early breast cancer: 15 -year results of a prospective non-randomised trial," European Journal of Cancer, vol. 51, no. 11, pp. 1358-1364, 2015.

[125] F. Keime-Guibert, O. Chinot, L. Taillandier et al., "Radiotherapy for Glioblastoma in the Elderly," The New England Journal of Medicine, vol. 356, no. 15, pp. 1527-1535, 2007.

[126] J. Pignon, J. Bourhis, C. Domenge, and L. Designé, “Chemotherapy added to locoregional treatment for head and neck squamous-cell carcinoma: three meta-analyses of updated individual data," The Lancet, vol. 355, no. 9208, pp. 949-955, 2000.

[127] A. A. Secord, M. A. Geller, G. Broadwater et al., "A multicenter evaluation of adjuvant therapy in women with optimally resected stage IIIC endometrial cancer," Gynecologic Oncology, vol. 128, no. 1, pp. 65-70, 2013.

[128] R. Stupp, W. P. Mason, M. J. van den Bent et al., "Radiotherapy plus concomitant and adjuvant temozolomide for glioblastoma," The New England Journal of Medicine, vol. 352, no. 10, pp. 987-996, 2005.

[129] P. Warde and D. Payne, "Does thoracic irradiation improve survival and local control in limited-stage small-cell carcinoma of the lung? A meta-analysis," Journal of Clinical Oncology, vol. 10, no. 6, pp. 890-895, 1992.

[130] R. Sawhney, M. Sehl, and A. Naeim, "Physiologic aspects of aging: Impact on cancer management and decision making, part I," Cancer Journal, vol. 11, no. 6, pp. 449-460, 2005.

[131] M. Sehl, R. Sawhney, and A. Naeim, "Physiologic aspects of aging: Impact on cancer management and decision making, part II," Cancer Journal, vol. 11, no. 6, pp. 461-473, 2005.

[132] T. J. Strom, A. O. Naghavi, A. M. Trotti et al., "Increased acute mortality with chemoradiotherapy for locally advanced head and neck cancer in patients $\geq 70$ years," Journal of Geriatric Oncology, vol. 8, no. 1, pp. 50-55, 2016.

[133] E. Metcalfe, O. Karaoglanoglu, and E. Akyazici, "Radiotherapy with or without temozolomide in elderly patients aged $\geq 70$ years with glioblastoma," Wspolczesna Onkologia, vol. 20, no. 3, pp. 251-255, 2016.

[134] V. Guimas, J. Boustani, B. Schipman et al., "Preoperative chemoradiotherapy for rectal cancer in patients aged 75 years and older: acute toxicity, compliance with treatment, and early results," Drugs \& Aging, vol. 33, no. 6, pp. 419-425, 2016.

[135] F. Cardenal, E. Nadal, M. Jove, and C. Faivre-Finn, "Concurrent systemic therapy with radiotherapy for the treatment of poorrisk patients with unresectable stage III non-small-cell lung cancer: A review of the literature," Annals of Oncology, vol. 26, no. 2, pp. 278-288, 2015.

[136] A. H. Klopp, J. Moughan, L. Portelance et al., "Hematologic toxicity in RTOG 0418: A phase 2 study of postoperative IMRT for gynecologic cancer," International Journal of Radiation Oncology • Biology•Physics, vol. 86, no. 1, pp. 83-90, 2013.

[137] N. Nguyen, W. Shen, S. Kratz et al., "Feasibility of tomotherapybased image-guided radiotherapy for small cell lung cancer," Frontiers in Oncology, vol. 3, 2013.

[138] M. Uto, T. Mizowaki, K. Ogura et al., "Feasibility evaluation of hypofractionated radiotherapy with concurrent temozolomide 
in elderly patients with glioblastoma," International Journal of Clinical Oncology, vol. 21, no. 6, pp. 1023-1029, 2016.

[139] D. De Ruysscher and J. van Loon, "Radical radiotherapy for locally advanced non-small cell lung cancer: when should concurrent chemoradiotherapy not be used?" Clinical Oncology, vol. 28, no. 11, pp. 708-711, 2016.

[140] Q. Zeng, J. Wang, X. Lv et al., "Induction Chemotherapy Followed by Radiotherapy versus Concurrent Chemoradiotherapy in elderly patients with nasopharyngeal carcinoma: Finding from a propensity-matched analysis," BMC Cancer, vol. 16, no. 1, article 693, 2016.

[141] G. L. Smith and B. D. Smith, "Radiation treatment in older patients: a framework for clinical decision making," Journal of Clinical Oncology, vol. 32, no. 24, pp. 2669-2678, 2014.

[142] M. T. E. Puts, J. Hardt, J. Monette, V. Girre, E. Springall, and S. M. H. Alibhai, "Use of geriatric assessment for older adults in the oncology setting: a systematic review," Journal of the National Cancer Institute, vol. 104, no. 15, pp. 1134-1164, 2012.

[143] J. S. Temel, J. A. Greer, A. Muzikansky et al., "Early palliative care for patients with metastatic non-small-cell lung cancer," The New England Journal of Medicine, vol. 363, no. 8, pp. 733742, 2010.

[144] K. M. Kash, R. Mago, and E. J. S. Kunkel, "Psychosocial oncology: Supportive care for the cancer patient," Seminars in Oncology, vol. 32, no. 2, pp. 211-218, 2005. 


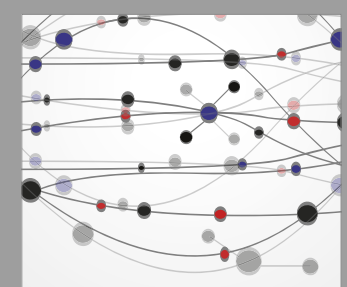

The Scientific World Journal
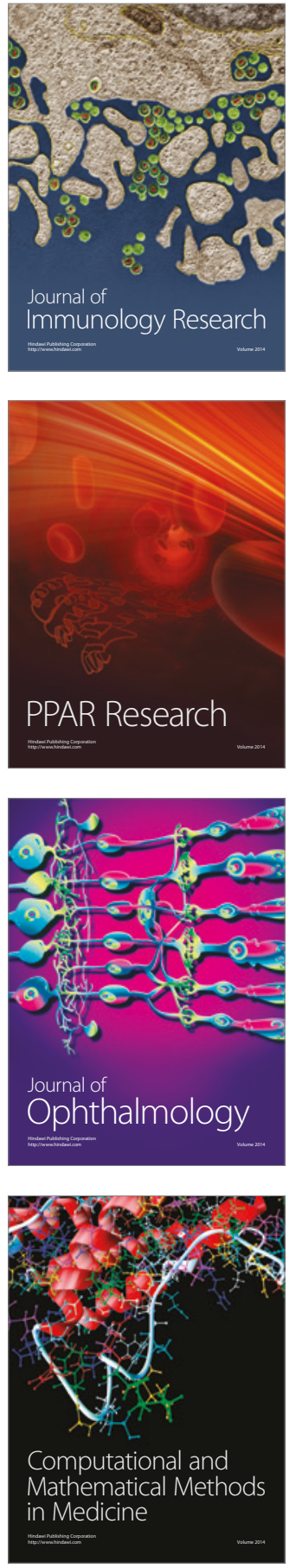

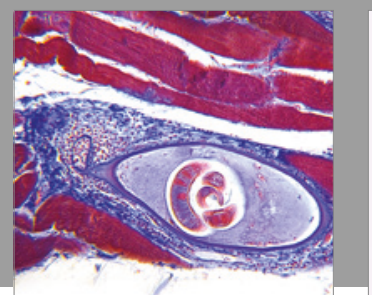

Gastroenterology Research and Practice
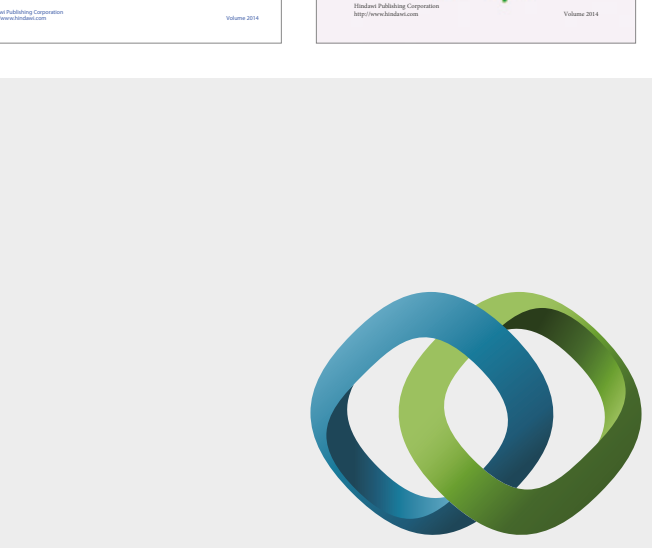

\section{Hindawi}

Submit your manuscripts at

https://www.hindawi.com
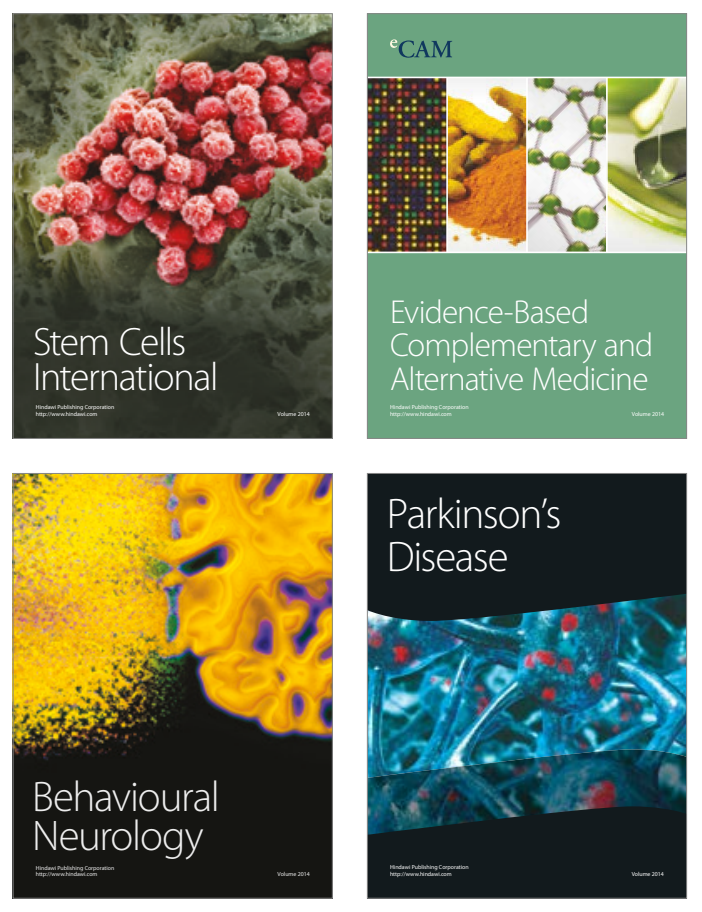
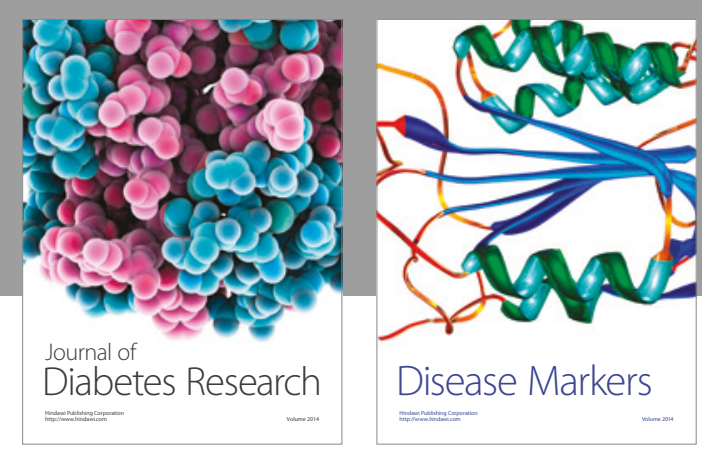

Disease Markers
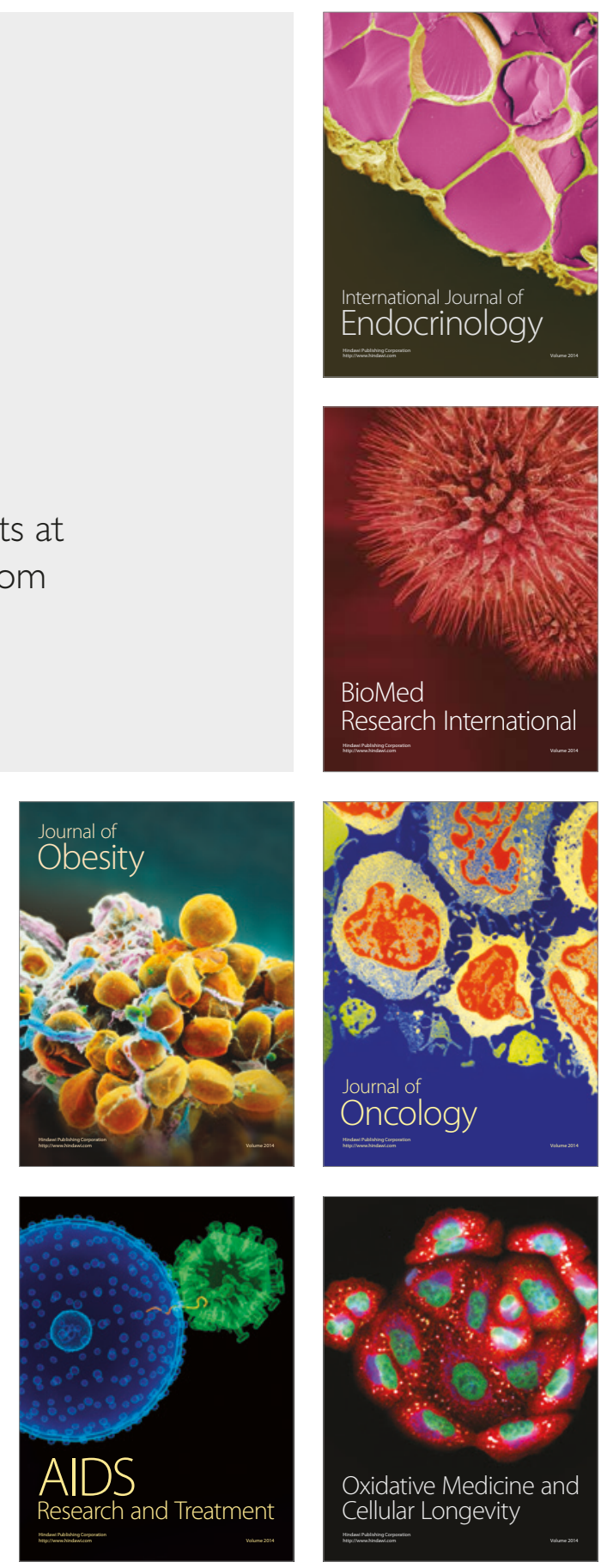